\title{
Agencias trasnacionales y desarrollismo en dictadura: Análisis del plan MEC-OEA para la enseñanza media básica de Uruguay en 1975
}

\author{
Transnational agencies and developmentalism in dictatorship: \\ Analysis of the MEC-OEA plan for basic secondary education in \\ Uruguay in 1975
}

\author{
Leonor Berná \\ Instituto de Formación Docente \\ Administración Nacional de Educación Pública \\ (ANEP), Montevideo, Uruguay, \\ leonorberna@gmail.com
}

DOI: 10.21680/2596-0113.2021v4n0ID25765

Citation: Berná, L. (2021). Agencias trasnacionales y desarrollismo en dictadura: Análisis del plan MEC-OEA para la enseñanza media básica de Uruguay en 1975. History of Education in Latin America - HistELA, 4, e25765.

Competing interests: The authors have declared that no competing interests exist.

Editor: Olivia Morais de Medeiros Neta

Received: 29/06/2021

Approved: 29/10/2021

OPEN ACCESS

\begin{abstract}
Resumen
Este artículo estudia el proyecto curricular para la enseñanza media que elaboraron en forma conjunta el Ministerio de Educación y Cultura de Uruguay y la Organización de Estados Americanos entre 1973 y 1975. El análisis crítico de esta fuente primaria inédita y un relevamiento general de documentos de las agencias internacionales, demuestra la centralidad del discurso desarrollista tecnocrático en la década de 1970. Dentro de las nociones y propuestas de la planificación educativa abocada a la formación de recursos humanos para el desarrollo, se proyectó una pedagogía instrumental que buscó preparar al alumno para el nuevo mundo productivo. Esta perspectiva, no solo fue una de las matrices de la política educativa de la dictadura, sino que perdura hasta la actualidad.
\end{abstract}

Palabras clave: Enseñanza media. Dictadura. Desarrollismo.

\begin{abstract}
This article studies the curricular project for secondary education that the Ministry of Education and Culture in Uruguay and the Organization of American States developed together between 1973 and 1975. The critical analysis of this unpublished primary source and a general survey of documents from the international agencies shows the centrality of the technocratic developmental discourse in the 1970s. Along with the notions and proposals of educational planning aimed at training human resources for development, an instrumental pedagogy was projected, which sought to prepare the student for the new productive world. This perspective was one of the matrices of the educational policy of the dictatorship, and also it continues until the present.
\end{abstract}

Keywords: Secondary education. Dictatorship. Developmentalism. 


\section{Introducción}

El 16 de enero de 1973, el diario El País publicaba un editorial titulado Educación y desarrollo. En él se manifestaba que la educación, no solo debía asegurar la formación de hábitos morales y cívicos, sino que tenía otra tarea igualmente noble: la de servir a la evolución económica de los pueblos. Para respaldar este razonamiento transcribían declaraciones de dos actores destacados, uno local, la Comisión de Inversiones y Desarrollo Económico (CIDE), y otro internacional, la Organización de Estados Americanos (OEA). Según el enfoque desarrollista que promovían ambas instituciones, para mejorar las condiciones de vida de los pueblos había que coordinar el campo económico con el educacional y planificar la formación de recursos humanos afines a las demandas científicas y tecnológicas para un crecimiento económico acelerado (El País, 1973, p. 5). ${ }^{1}$

Este alegato en la prensa no fue casual. Unos pocos días antes se había aprobado la Ley de Educación General 14.101. Esta normativa modificó los fines de la educación para orientarlos a contribuir a las necesidades del desarrollo nacional. Para centralizar esta tarea, se dispuso la creación de una Oficina de Planeamiento Educativo en la órbita del Ministerio de Educación y Cultura (MEC). Desde su origen, esta institución trabajó en forma conjunta con el Programa Regional de Desarrollo Educativo de la OEA. De esta actividad asociada de 28 meses en dos proyectos distintos (Currículum y Desarrollo y Currículum de Educación Básica) surgió una propuesta de reforma de la enseñanza media. La misma se divulgó en 1975 en una publicación titulada Desarrollo de currículum, que hallamos en la Biblioteca Nacional (Ministerio de Educación y Cultura [MEC] \& Organización de Estados Americanos [OEA], 1975, p.16).

Por otra parte, la Ley 14.101 estableció como meta en su artículo primero, "la defensa de la soberanía nacional, el orden y la seguridad integral del Estado". Para el gobierno y los actores que apoyarían el golpe de Estado, la actitud contestataria de los estudiantes (desplegada en asambleas, paros, ocupaciones de liceos 0 contracursos sobre Paulo Freire, entre otras manifestaciones) era un componente central de la estrategia del marxismo global destinada a sembrar la anarquía y el caos, con fines políticos. Esta retórica, común a varios países del continente en los años 1970, estaba alineada con la Doctrina de la Seguridad Nacional difundida por Estados Unidos, en el marco de la Guerra Fría. En consecuencia, para imponer el orden, la legislación incluyó un extenso articulado de corte represivo y reconfiguró la arquitectura institucional, eliminando la autonomía y la representación docente de la estructura de gobierno del sistema educativo. En su lugar se creó un nuevo Consejo Nacional de Educación (CONAE), conformado por cinco miembros designados directamente por el Poder Ejecutivo. ${ }^{2}$ Estos cambios representaron una brusca ruptura con la tradición del país que tenía una dirección de la enseñanza articulada al cuerpo de profesores, que funcionaba con independencia de los vaivenes políticopartidarios y defendía valores como la laicidad, el fomento del espíritu crítico y la libertad creativa del docente (Rodríguez de Artucio et al., 1985, p. 57).

La reflexión historiográfica acuerda, en términos generales, que la política educativa de la dictadura en Uruguay no fue clara ni tuvo un plan expreso totalmente definido. ${ }^{3}$ Para Silvia Campodónico, Ema Massera y Niurka Sala (1991) la filosofía educativa del régimen resultó de la amalgama de un conjunto de tendencias, bajo la hegemonía del catolicismo nacionalista de ultraderecha y la Doctrina de la Seguridad Nacional. En el mismo sentido, para Antonio Romano (2010) la pedagogía del régimen 
autoritario, si bien fue explicitada más en actos que en formulaciones teóricas, demostró la voluntad de las Fuerzas Armadas por utilizar el proyecto educativo como instrumento de su proyecto político conservador. Por consiguiente, para (re)fundar los cimientos de la "nueva" República, se le asignó a la enseñanza la tarea de combatir aquellas formas doctrinarias "impuras" que debilitaban el sentimiento nacionalista y afirmar una doctrina capaz de formar al nuevo hombre uruguayo.

Más recientemente, estudios enfocados en la década de 1960 han observado la presencia de la perspectiva desarrollista en el campo educativo. Romano (2013) visualiza en este período un desplazamiento en los métodos de abordaje de la educación desde la teoría pedagógica hacia la economía. De acuerdo a su interpretación, la difusión de las teorías desarrollistas impulsó la hegemonía de la mirada económica en la investigación y la planificación de la realidad educativa. Continuando esta tarea, Lucas D’Avenia $(2013,2014)$ profundizó en los formatos de esta orientación, con especial atención en los documentos producidos por la CIDE. ${ }^{4}$ Dentro del impulso dado por este organismo a la planificación de políticas públicas racionales, integrales y eficientes, se destaca el lugar primordial asignado a la educación como promotor de las metas de crecimiento económico y posibilidades ocupacionales. Su investigación explica, además, que confluyeron en aquel desarrollismo procesos diferentes y que hubo múltiples traducciones que habilitan a pensarlo como un campo en disputa. Desde esta visión renovada, D'Avenia (2013, 2016) encuentra rastros de la retórica desarrollista en los lineamientos educativos de las décadas siguientes, en particular en el articulado de la Ley 14.101 y de los cónclaves gubernamentales de la dictadura militar. ${ }^{5}$

Es interesante reparar que la década de 1960 también fue, a nivel internacional, como apunta Claudio Suasnábar (2013), la "época dorada" de los organismos multinacionales dedicados a la promoción del enfoque desarrollista en la educación (p. 106). De hecho, el paradigma del planeamiento educativo fue la base de las reformas que se impulsaron en Europa occidental al menos hasta el decenio de 1970 (De Puelles, s. f.).

Desde este eje de análisis, el presente artículo es tributario de un nuevo enfoque de la Historia de la Educación, interesado por los impactos de los nexos internacionales en las narrativas educativas nacionales. Específicamente, de la vertiente dedicada a comprender en qué medida la promoción de políticas educativas semejantes a nivel mundial, podrían explicarse por la mediación ejercida por instituciones trasnacionales como la Organización de las Naciones Unidas para la Educación, la Ciencia y la Cultura (UNESCO), la OEA o el Banco Mundial, entre otras. Estas agencias, no solo fueron una usina de producción de conocimiento, sino que desplegaron una diplomacia intervencionista, con préstamos anexados a lineamientos o "recomendaciones", programas de asistencia técnica, encuentros y hasta experiencias puntuales como el dictado de cursos o la donación de insumos.

En este tipo de investigaciones, la internacionalización se volvió una categoría medular. Jürgen Schriewer (2011) la define como una etapa histórica donde se intensificaron las relaciones globales de interacción e intercambio, producto del dominio contemporáneo del espacio (pp. 41-42). Asimismo, la entiende como una herramienta central del análisis histórico para entender los flujos y redes de transferencia de modelos e ideas educativas, tal cual lo hacen los estudios comparativos de educación. No obstante, el mismo autor advierte que estos procesos internacionales de difusión y recepción tienen una naturaleza no lineal y contingente. 
En este sentido, Jason Beech (2011) propone emplear una metodología historicista, para poder captar los procesos de indigenización -como los denomina Schriewer- y develar cómo estos modelos diseñados globalmente se entrelazan con los contextos locales y son reinterpretados y recontextualizados en un determinado tiempo y espacio.

Este artículo se propone trabajar en esta perspectiva y complejizar el entramado ideológico del proyecto político pedagógico de la dictadura. Para ello, se incorpora a la reflexión una reforma curricular para la enseñanza media, hasta ahora inexplorada y que fuera diseñada con la colaboración directa de organismos internacionales. Se busca probar que esta propuesta constituye un desarrollismo conservador, que recoge algunas nociones vinculadas a la matriz ideológica conservadora, junto a la influencia de la orientación desarrollista y tecnocrática.

Este trabajo se inscribe en una investigación de doctorado, aún en curso, sobre las transformaciones de Educación Secundaria en dictadura. A nivel metodológico, se utiliza una revisión histórica de carácter cualitativo, que articula el análisis de diversos grupos documentales. Se trata de fuentes primarias, éditas e inéditas, como las actas de sesiones del Consejo de Secundaria y del CONAE, actas del Consejo de Estado, revistas del MEC en dictadura y diversas publicaciones de organismos internacionales. Además, resultaron de utilidad las notas de la prensa, conteniendo comunicados oficiales, columnas de opinión y reflexiones de muchos jerarcas, técnicos y referentes en la temática educativa. ${ }^{6}$

El texto está organizado en tres apartados. El primero busca contextualizar el paradigma de la planificación desarrollista que se propagó a través de una red de actividades trasnacionales, en las que Uruguay tuvo una participación activa. Aunque esta temática no ha sido abordada específicamente por la historiografía uruguaya, los trabajos de países vecinos y las publicaciones de estas instituciones permiten evidenciar la potencia de esta convergencia discursiva. En el segundo apartado se examinan las orientaciones y finalidades formativas del nuevo currículo para la Educación Media Básica. Con ello se espera caracterizar, tanto los cometidos u objetivos generales del plan, como el nuevo perfil del alumno. Finalmente, el tercer apartado considera la propuesta de estructura curricular. Para ello, se observan las pautas de distribución del tiempo y áreas de conocimiento, las metodologías de enseñanza y evaluación privilegiadas y la preparación del cuerpo docente.

\section{El contexto desarrollista de la planificación educativa}

En América Latina la agenda cultural desarrollista se consolidó junto a los procesos de industrialización sustitutiva de importaciones y la democratización de los sistemas educativos, abocados entonces a la formación de "ciudadanos" que tuvieran las herramientas básicas para participar en el mundo productivo y en el mundo social (García, 2008). Este proceso resultó convergente con el marco reflexivo y operativo desarrollista, promovido principalmente por la UNESCO y la OEA y luego por la Comisión Económica para América Latina (CEPAL). A los que se agrega también la Alianza para el Progreso desplegada por Estados Unidos, en el escenario de radicalización de la Guerra Fría (Suasnábar, 2013).

En este contexto, se consolidó una suerte de mística acerca del papel de la educación como pieza clave del proceso de desarrollo de las naciones. La premisa de esta teoría era la relación virtuosa entre educación, industrialización y crecimiento 
económico acelerado. Para este engranaje se requería planificar la producción de recursos humanos en función de las demandas del modelo de acumulación capitalista. ${ }^{7}$ Es decir, se instaba a modernizar el sistema educativo para adaptarlo a un mundo que se suponía cada vez más tecnificado y por lo tanto, requería de sujetos con determinadas habilidades y conocimientos para ser económicamente productivos. A su vez, desde esta racionalidad técnica y de fuerte sesgo economicista, se derivó una nueva pedagogía con pretensiones de objetividad. Una forma de analizar los problemas escolares basada en indicadores objetivos, estudios de costobeneficio, racionalidad de los recursos, etcétera (García, 2008, pp.3-5).

La documentación de estos organismos prueba que Uruguay cooperó activamente en los diversos emprendimientos y proyectos. A modo ilustrativo se mencionan algunas de estas redes. La UNESCO poseía una sucursal del Instituto Internacional de Planificación de la Educación en Chile. Desde esta oficina regional, se organizó un encuentro en Venezuela en 1974, al que asistió un representante del MEC. Este seminario se presentó como un paso muy importante en el esfuerzo de los países para reorientar y renovar el contenido de la educación y elevar los niveles de calidad de sus resultados (UNESCO. Oficina Regional de Educación. Santiago de Chile, 1974).

En paralelo, Uruguay participó del Instituto Latinoamericano de Planificación Económica y Social de la CEPAL. ${ }^{8}$ En la Conferencia Regional de Ministros de Educación y ministros encargados de la Planificación Económica, que se realizó en México en 1979, se acordó que ningún país podría avanzar en su desarrollo más allá de donde llegara su educación y se aconsejó transformar el currículo procurando articular los sistemas educativos y el mundo del trabajo (UNESCO, CEPAL, OEA, 1979) ${ }^{9}$. Desde esta plataforma se forjó, además, el Proyecto Principal de Educación en América Latina y el Caribe que se articuló a partir de 1981.

En este circuito, otro espacio destacado fue el proyecto denominado Desarrollo y Educación en América Latina y el Caribe vinculado a UNESCO, CEPAL y el Programa de las Naciones Unidas para el Desarrollo (PNUD). Este extenso programa de investigación, desplegado entre 1975 y 1981, reunió a centros académicos, expertos y equipos técnicos de los gobiernos, coordinados por el profesor uruguayo Germán Rama. La singularidad de este esfuerzo estuvo dada en la renovación de la perspectiva del desarrollismo-funcionalista (Causa, 2009). ${ }^{10}$

Por último, en este breve repertorio también debe incluirse a la OEA, que, desde 1972, organizó el Programa Regional de Desarrollo Educativo, coordinado en Uruguay por la Oficina de Planeamiento Educativo del MEC. ${ }^{11}$ Desde estas instituciones se desarrollaron al menos dos trabajos importantes. El primero fue una réplica de la investigación realizada por la sede de la OEA en Argentina, sobre los niveles de la enseñanza media. Esta problemática fue abordada desde variables cuantitativas como la aprobación, repitencia y deserción y sus resultados se publicaron en 1974, con el nombre de Algunos aspectos del rendimiento escolar. ${ }^{12}$ Un año más tarde, se divulgó la segunda investigación, que es el libro que se considera en este texto: Desarrollo de Currículum. El mismo contó con la colaboración de especialistas extranjeros. Entre ellos se destaca la presencia de dos expertos argentinos: Ricardo Bruera y Benicio Villarreal. Ambos jerarcas tuvieron una labor destacada en la dictadura (uno como ministro de la Nación Argentina y el otro como subsecretario de Educación en Argentina) y, según documenta Laura G. Rodríguez (2013), pueden identificarse como católicos desarrollistas. 
Esta última publicación contiene una fundamentación de la propuesta del Ciclo de Educación Secundaria Básica, que incluye objetivos, contenidos y evaluación, así como el diseño curricular para el área de Ciencias, de Ciencias Sociales, de Idioma Español y Matemáticas. También se incluye un esquema general de reforma del sistema educativa (analizando cada uno de sus niveles), un capítulo dedicado a la preparación de los recursos humanos, algunas opiniones del personal docente sobre la enseñanza de las ciencias y las ciencias sociales y, por último, un anteproyecto de un servicio de Orientación.

Para los redactores del MEC y la OEA, este proyecto se presentaba en un momento de máxima trascendencia para el futuro nacional, dada la necesidad de adecuar la organización escolar a las metas de desarrollo global del país. Desde su perspectiva "las necesidades ocupacionales de la sociedad establecen los requerimientos formativos y las capacitaciones profesionales para constituir el encuadre estructural básico del sistema educativo" (MEC-OEA, 1975, p. 89). Este objetivo presuponía una planificación solvente, que había demandado más de dos años de labor y que confiaban terminaría por imponerse (MEC-OEA, 1974, p. 15). Esta formulación pretendía exhibir la propuesta como una elaboración en manos de expertos, supuestamente ajenos a la política y, por lo tanto, como una solución técnica, racional e ideológicamente neutra.

\section{Orientación y finalidades formativas de la nueva Educación Media Básica}

La publicación de MEC-OEA (1975) evaluaba la realidad de la enseñanza media, poniendo el foco en las deficiencias derivadas de la masificación de la matrícula y en la falta de actualidad de los diversos planes de estudio. El plan más extendido era del año 1941, y existían además dos planes pilotos, uno del año 1963 y otro para liceos nocturnos (para población que trabajaba) del año $1968 .{ }^{13}$ La crítica que realizaban no era la falta de homogeneidad curricular, sino que ninguno acompasaba las nuevas corrientes pedagógicas, ni la realidad científica y socioeconómica del país y del mundo. En consecuencia, proponían un proyecto que permitiera mejorar el rendimiento del sistema escolar y adecuar la educación a los requerimientos formativos para alcanzar el progreso socio-económico. En sus palabras "nadie discute en el mundo moderno que la educación es entonces una inversión en el sentido de que debe impartirse para el trabajo productivo"(MEC-OEA, 1975, p.79).

Para definir los propósitos de la educación se amparaban en la Ley 14.101 y defendían una formación integral. Este objetivo se interpretaba como aquella enseñanza que, además del tradicional humanismo, hiciera énfasis en la cultura científica. Se juzgaba que el mundo estaba en permanente mutación, con cambios acelerados en todos los órdenes, y el individuo, lo aceptara o no, estaba proyectado en un entorno impregnado de ciencia. Por lo tanto, citando un Informe de la UNESCO de 1972 titulado Aprender a ser, afirmaban que solamente se podría comprender el universo donde uno estaba situado si se poseían las claves del conocimiento científico. En términos pragmáticos, se explicaba que el trabajador, a futuro, únicamente podría participar en la producción en la medida que fuera capaz, no solo de aplicar un cierto número de procedimientos científicos, sino además de comprenderlos. En tal sentido, se reclamaba eliminar los cánones enciclopedistas y 
entrecruzar los caminos de la escuela y la vida, postulando que interesaba menos poseer un acervo de conocimientos que hallarse iniciado en la metodología científica. De modo que se le asignaba a la educación un cometido instrumental y se levantaba la bandera de enseñar a "aprender a aprender, a aprender a ser, a aprender a hacer" (MEC-OEA, 1975, p. 78).

El proyecto curricular establecía objetivos para el campo de los conocimientos, el campo de las habilidades y el campo de las actitudes y valores. Los mismos se desglosaban en aspectos muy diversos y abarcaban desde capacidades concretas como "expresarse correctamente" hasta otras más generales como "fortalecer el sentido de comprensión y solidaridad internacional". En relación al fomento de habilidades, esta escuela del futuro procuraba que el estudiante adquiriera "habilidad manual [...]para realizar con eficacia las tareas de la vida corriente" pero además, se buscaba que pudiera afrontar el mundo laboral donde se necesitaba "autonomía, iniciativa, responsabilidad" y se desenvolviera en cooperación con otros, en la elaboración no directiva y el autocontrol (MEC-OEA, 1975, pp. 85-90).

Por otra parte, algunas de los objetivos traducen nociones que se pueden asociar a los discursos oficiales más conservadores. No sabemos a ciencia cierta si los introdujeron para obtener la aprobación de jerarcas con esta base ideológica, como los ministros de educación de la época Edmundo Narancio o Daniel Darracq, o si, por el contrario, suscribían estos principios. A modo de ejemplo: se propone que el educando logre conocer y amar a la patria, familiarizándolo con su geografía, su historia, sus tradiciones y el respeto hacia los símbolos nacionales. Se define formar para el ejercicio de la "libertad responsable", entendida como el deseo de plasmar en el estudiante un claro sentido de responsabilidad, tanto en la vida individual como social, y enseñarle "a expresar con prudente libertad sus ideas, a escuchar al interlocutor y a considerar las ideas correctamente fundadas" (MEC-OEA, 1975, p.84). Asimismo, se busca informar acerca del mundo ocupacional, promoviendo una actitud de participación positiva en las metas del Proceso de Desarrollo Nacional impulsado por la dictadura.

En este largo y puntilloso listado de finalidades educativas también hubo lugar para el propósito de formar en los deberes y derechos de la persona humana. Esta construcción discursiva que dice defender el régimen democrático republicano es la misma a la que recurrió el gobierno de facto. Pero solo desde su propósito propagandístico se puede entender que, por ejemplo, se proponga "trabajar el respeto a la dignidad y libertades fundamentales", en el marco de una dictadura que violentaba permanentemente los preceptos que decía defender.

Esta resignificación de la educación se acompañó de una fundamentación vinculada a las formas de actuación, tendencias y perfiles de maduración del educando en una determinada etapa evolutiva. Se concebía el crecimiento como un proceso de formación de patrones de conducta mediado por factores bío-psíquicos, socio-económicos y culturales. Por consiguiente, se planteaba que el proceso de enseñanza debía atender las características generales de los distintos niveles cronológicos, así como también las diferencias entre niñas y varones. Estas últimas, eran detalladas en un cuadro que especificaba las principales características de cada género. Así, por ejemplo, se definía que los varones eran superiores en ciencias y matemáticas o en comprensión verbal, mientras que las niñas los aventajan en idiomas y memoria. $O$ se precisaba que los estudiantes eran inquietos, activos y competitivos, mientras que las estudiantes eran disciplinadas, sedentarias e 
interesadas por la apariencia y los modales. Estas tipologías resultan representativas de los estereotipos de la sociedad conservadora y patriarcal (MEC-OEA, 1975, p.102).

Para desarrollar estas potencialidades individuales el proyecto le asignó un lugar desatacado a la orientación. Definida como el "hilo conductor" de la organización curricular, este servicio ayudaría a los educandos a realizar una elección consciente, que atendiera sus intereses y sus habilidades en los distintos campos del saber. Pero sobre todo, para los autores la orientación era el nudo de toda reforma, en tanto convergían en ella, la preocupación de la formación del individuo para sí mismo y la de prepararlo para la función social que debía desempeñar. De esta forma, la consideración de los intereses de los alumnos permitiría una correcta "ubicación" de cada uno de los miembros de la sociedad y, por ende, una convivencia más armónica y un rendimiento superior en las esferas de la educación y el trabajo, al eliminarse frustraciones que podían desencadenar agresividad (MEC-OEA, 1975, p. 93).

El sustrato teórico de este planteo asumía que solo bastaba con encontrar las vocaciones, o más exactamente las habilidades o destrezas del sujeto, para que éste encontrara su lugar dentro de la sociedad y, como resultado, se comportara correctamente. Al mismo tiempo, esta narrativa se quiso mostrar como democratizadora, convocando a que no hubiera más discriminaciones que las que provinieran de los méritos individuales. Esto quiere decir que se fomentó una concepción meritocrática, que estaría destinada a perdurar varias décadas en el discurso pedagógico.

\section{Estructura curricular, recursos humanos y evaluación}

La propuesta de organización académica del Ciclo Básico comprendía tres tipos de secciones: asignaturas obligatorias $(79,4 \%)$, optativas $(11,8 \%)$ y libres $(8,8 \%)$. Dentro del espacio obligatorio, la principal novedad fue la enseñanza por áreas. Se proyectaron cuatro áreas denominadas: La Materia y EI Número, La Vida, El Hombre y La Expresión. Las mismas debían ser conducidas por personal docente especializado. Para el MEC y la OEA, se trataba de que el profesor realizara una síntesis mental previa, que luego transmitía a sus alumnos a través de una sola acción didáctica, no de que dictara varias disciplinas. Este cambio era concebido como una respuesta a los procesos mentales propios del alumno en la pubertad y pretendía proporcionar la agilidad y eficacia necesarias para estimular a los educandos de este nivel.

En el espacio de actividades optativas se ofrecerían talleres de manualidades o educación pre-técnica. Cada alumno obtendría con ellos dos créditos, que podían cursarse en cualquier establecimiento, incluidos talleres particulares. Se puntualizaba, en pos de una mayor eficiencia, el interés por aprovechar la capacidad locativa de instituciones privadas y la utilización compartida de los edificios escolares, que dejarían de ser de uso exclusivo de cada uno de los Consejos.

Otra iniciativa importante fue el otorgamiento de títulos escalonados con salida laboral. El nuevo plan de estudios preveía un carácter de terminalidad para aquellos alumnos que debieran afrontar tempranamente el campo laboral. Con este espíritu, se pretendía equilibrar las asignaturas de cultura general y las de orientación laboral, así como la esfera teórica y práctica de cada materia. Inclusive en la enseñanza superior (quinto y sexto año) se proyectaban "bachilleratos modalizados", que respondieran a las necesidades de diversificación zonal y laboral. ${ }^{14}$ 
En relación al horario, la publicación MEC-OEA establece que no creían conveniente implantar la doble escolaridad, como había sido sugerido poco tiempo atrás por el CONAE en un proyecto que naufraga. Esta práctica, con tradición centenaria en el sector privado, se desaconsejaba a nivel público, con el único argumento del alto costo y la necesidad de un currículum enriquecido con una diversidad de actividades. De lo contrario, a juicio de estos organismos, se terminaba por aumentar la deserción, sobre todo en el ámbito rural donde el niño no podría ausentarse todo el día porque prestaba alguna pequeña ayuda laboral para el sustento de su familia. Se agregaba, además, el inconveniente de "sustraer al niño de la influencia de la familia y generar la costumbre de esperarlo todo del Estado: instrucción, comida, transporte, recreación, etc." (MEC-OEA, 1975, p. 73). Estas últimas justificaciones, además de configurar un apoyo velado del trabajo infantil, se ensamblaban con la crítica al rol benefactor del Estado, que también tuvo desde la ideología neoliberal fieles paladines durante la dictadura.

Por otro lado, la configuración curricular de este proyecto hizo foco en los recursos humanos destinados a impulsar esta empresa. Esta prioridad motivó varias sugerencias vinculadas a la formación, capacitación y perfeccionamiento del personal docente. A nivel estructural, se promovió la unidad orgánica de todo el sistema, reuniendo las diversas instituciones de formación docente en una única Dirección de Educación Superior. Esta institución debería delinear el nuevo plan de estudios, integrando las tendencias más actualizadas a nivel científico, epistemológico y pedagógico. ${ }^{15}$ En paralelo, el MEC y la OEA impulsaron la creación de Institutos de Formación docente en el sector privado, una Escuela de Capacitación Directiva y Técnica para directores y supervisores y una Facultad o Instituto Superior de Ciencias de la Educación. Varias de estas medidas se terminaron concretando con la creación del Instituto Nacional Docente General Artigas y un nuevo Plan de Formación Docente en 1977.

En sintonía con esta reestructura, el proyecto MEC-OEA definió un nuevo perfil del docente del Ciclo Básico. Esta profesión, que catalogaron como un verdadero sacerdocio laico, requería tener una serie muy amplia de cualidades, que le permitieran afrontar un rol cada día más complejo (MEC-OEA, 1975, p. 38). A nivel general se debía contar con: un profundo respeto a la conciencia del educando, capacidad para trasmitir y sintetizar conocimientos, acabado dominio de la pedagogía y la psicología, amplia capacidad de disposición para la renovación y el perfeccionamiento, entre otras facultades. Como condiciones específicas para este nivel, se reclamaba: buenos conocimientos de las disciplinas del área, aptitud para adaptar la enseñanza al medio, actitud de trabajo en equipo, disposición especial para una permanente autoevaluación, etcétera. Como si todo esto no fuera suficiente, el docente debían reunir rasgos caracterológicos y físicos: estabilidad emocional y psíquica, gran comunicación y sociabilidad, buena salud física, buena presencia, buena pantomima, ser un modelo de conducta en lo moral, ser un verdadero consejero-guía del educando y contar con una personalidad equilibrada (MEC-OEA, 1975, pp. 38-40). ${ }^{16}$

Por último, el proyecto hace un tratamiento especial para el tema de la evaluación. La misma se definía como la capacidad de determinar el grado en que se verificaban cambios en los esquemas conductuales del estudiante. Se razonaba que la acción educativa se circunscribía a tres tareas: determinar objetivos, seleccionar el contenido y las estrategias que mejor se ajustaran a los objetivos fijados, y luego, evaluar en base a estas pautas. Por lo tanto, los objetivos debían describir de manera 
precisa el cambio a nivel de los conocimientos, las habilidades y las actitudes que debían ocurrir como resultado del proceso de enseñanza-aprendizaje. Pero al mismo tiempo, la evaluación configuraba una herramienta central para estudiar e interpretar la congruencia entre los objetivos que se propuso el profesor, el programa o el plan y logros alcanzados. De esta forma, se aportarían insumos para replanificar el trabajo del profesor y el liceo.

Desde esta concepción conductista, se mandataba que las prácticas de enseñanza debían planificarse con objetivos instruccionales u operacionales, es decir alusivas a destrezas observables y medibles que se esperaba que adquiriera el educando. Se explicitaban estos preceptos con ejemplos del tipo: "identifique en un dibujo las partes de un vegetal superior". Es decir, una consigna que trasmitiera sin ambigüedades la intención del profesor y definiera el comportamiento final que se esperaba del alumno (MEC-OEA, 1975, pp. 256-257).

De manera análoga, se proponía recurrir a "tests" de aptitudes, cuestionarios, entrevistas y otros medios que suministraran datos sobre el progreso de los estudiantes y sus eventuales dificultades (aportando información sobre qué necesitaban mejorar y cómo hacerlo). También se sugerían tres tipologías de evaluación: diagnóstica, formativa y sumativa. La primera servía para aportar información sobre las actitudes, habilidades y dificultades de los educandos. La segunda permitía reportar los rendimientos por objetivos o proyectos y replanificar los cursos. La tercera, valoraba el rendimiento escolar del alumno y posibilitaba verificar la efectividad de los objetivos y el currículum. Para acompañar estos formatos de evaluación se sugería la confección de fichas de observación y calificación, con las cuales realizar un seguimiento que valorara la serie de objetivos que tenía que alcanzar el alumno.

En síntesis, este modelo traduce los aportes de la Psicología del Aprendizaje, con una fuerte impronta conductista, donde se circunscribe la evaluación al trabajo por objetivos y se le da relevancia a las habilidades instrumentales en cada área específica. Los resultados se entienden como insumos para replanificar tanto el trabajo del profesor como de todo el liceo. Inclusive es importante notar que no aparece una preocupación por el orden y la disciplina, como podría esperarse de la reglamentación que circunscribía en la época los liceos.

\section{Algunas valoraciones a modo de cierre}

La propuesta de reforma de la enseñanza media de MEC-OEA en el contexto dictatorial permite introducir algunas novedades. La primera es la irrupción de nuevos actores en el campo educativo, como lo son las agencias internacionales. Si bien es un tema que todavía no se ha estudiado en profundidad, la revisión somera realizada para este trabajo da cuenta de la red de programas y proyectos que apuntaron a reestructurar las políticas educativas de la región.

A esta injerencia se añadió el proceso de elaboración político-pedagógico a través de comisiones de expertos y representantes políticos, que trabajaron por fuera de los Consejos de Enseñanza media. Este proceso profundizó la desarticulación de la autonomía del Ente e instauró una división del trabajo de fuerte impronta tecnocrática. 
Otra comprobación importante es la permanencia del enfoque desarrollista. Este anclaje no debería ser llamativo, en la medida que no solo enlaza con matrices ya presentes en Uruguay desde fines de los años 1950, sino que, paralelamente, fue la base de las agendas de los organismos internacionales y de las reformas educativas en países como España, a inicios de la década de 1970.

¿En qué aspectos se puede identificar esta mancomunión con el desarrollismo? En primer lugar, en los fines y la orientación general del nuevo currículum. Se considera al sistema educativo como una unidad y se reivindica la planificación y el diseño global de toda la política educacional. Esta tecnología social se vio favorecida por la unificación de los subsistemas educativos bajo la órbita del CONAE y el relevamiento de lo que se consideraba como indicadores objetivos, que habilitaban una gestión científica de la política curricular.

En segundo lugar, hay una mirada economicista preocupada por la mejora de los rendimientos escolares, deteriorados con la masificación del "servicio educativo". Esta clave de análisis introduce un eficientismo pedagógico (Nassif, 1981) que constituyó una preocupación compartida (¿disputada?) con el paradigma neoliberal. Conceptos empresariales como eficiencia, costo-eficacia, calidad, se volvieron moneda corriente en el discurso pedagógico.

En tercer lugar, se destaca el énfasis en el carácter profesionalizante de la educación. Para ello, se propuso un currículum más flexible y se priorizó la coordinación de la orientación vocacional y profesional con las necesidades de recursos humanos para el proceso productivo. Desde una conceptualización que vinculaba mecánicamente el sistema educativo y el aparato productivo, la justificación del proyecto MEC-OEA apuntó a la atención de las aptitudes e intereses del alumnado, pero también a la importancia de formar manos hábiles adecuadas al mundo laboral.

Otra noción destinada a perdurar, incluso teniendo una mayor preponderancia luego de la dictadura, fue la prioridad asignada a las competencias instrumentales sobre los contenidos de los diversos programas. En palabras del proyecto MEC-OEA "la educación cumplirá su cometido instrumental en la medida que enseñe a aprender a aprender" (MEC-OEA, 1975, p. 78). Por ende, los contenidos temáticos se concibieron articulados al uso una didáctica moderna, por momentos fuertemente conductista, que buscaba preparar al alumno para aprender por sí mismo y que pondera métodos y técnicas de enseñanza novedosos.

Por último, conscientes de la centralidad que ocupaban los profesores en cualquier proyecto de cambio, se previó una reestructura de la formación y el perfeccionamiento docente. La gestión de estos recursos humanos debía redireccionarse de acuerdo a los nuevos perfiles docentes. Si a esto agregamos las instrucciones metodológicas de los programas y el trabajo con objetivos operacionales para cada nivel mental, en el marco de esquemas conductuales, no quedaba casi margen para la iniciativa y autonomía profesional del profesor.

En suma, se puede concluir que este proyecto configuró un desarrollismo conservador, que ensambló principios afines a la ideología política conservadora, desvelada por fomentar el nacionalismo y el disciplinamiento, con una matriz desarrollista y tecnocrática, que buscaba adecuar la educación a los requerimientos formativos para promover el progreso socio-económico. Un lineamiento que tendería a perdurar en la pedagogía autoritaria. 


\section{Referencias bibliográficas}

Andreón, R. E. (1974). Educación y cambio. Prospectiva, pp. 7-12.

Beech, J. (2011). Continuidades y cambios en el campo educativo global. Influencias externas en la formación docente en Argentina y Brasil. En Internacionalización. Políticas educativas y reflexión pedagógica en un medio global (pp. 183-214). Granica.

Campodónico, S., Massera, E., \& Sala, N. (1991). Ideología y Educación durante la Dictadura. Antecedentes, Proyecto, Consecuencias. Banda Oriental.

Causa, M. (2009). Organismos internacionales y educación: Producción intelectual e innovación conceptual (1976-1989). 3(3), 141-156. http://www.fuentesmemoria.fahce.unlp.edu.ar/art_revistas/pr.4088/pr.4088.pdf

D’Avenia, L. (2013). Evolución de la estructura institucional y de la gestión de la educación pública en los últimos 50 años. Desafíos para la próxima década. $47 . \quad$ https://www.ineed.edu.uy/images/pdf/evolucion-de-educacionsecundaria.pdf

D'Avenia, L. (2014). Desarrollismo y educación en Uruguay en los 60. Contemporánea. Historia y problemas del siglo XX, 5, 147-167.

D'Avenia, L. (2016). Revisando continuidades. La agenda educativa de los cónclaves gubernamentales (1973-1981) durante la dictadura cívico-militar uruguaya. Políticas Educativas - PolEd, 9(1), 188-207.

De Puelles, M. (s. f.). Tecnocracia y política en la reforma educativa de 1970. Estudios. https://www.educacionyfp.gob.es/dam/jcr:d0b4eae4-2dde-4d229651-65550dba76ee/re199202-pdf.pdf

El País. (1973, enero 16). Educación y desarrollo. El País.

García, E. (2008). Auge y decadencia del desarrollismo en América Latina. Análisis desde una de sus estrategias centrales: El planeamiento de la educación. Revista Iberoamericana de Educación, 46(1), 1-18. https://doi.org/10.35362/rie4612014

Ministerio de Educación y Cultura \& Organización de Estados Americanos. (1974). Algunos aspectos del rendimiento escolar. IMCO.

Ministerio de Educación y Cultura \& Organización de Estados Americanos. (1975). Desarrollo de curriculum. IMCO.

Nassif, R. (1981, agosto). Las tendencias pedagógicas en América Latina (19601980). Informes finales II. UNESCO-CEPAL-PNUD. El cambio educativo. Situación y condiciones, 3, 89-119. 
Rodríguez de Artucio, E., Rampini, M. L., Tornaría, C., \& Mazzei, A. (1985). El proceso educativo uruguayo. Dos enfoques del modelo democrático al intento autoritario. Fondo de Cultura Universitaria.

Rodríguez, L. G. (2013). Los católicos desarrollistas en Argentina. Educación y planeamiento en los años de 1960. Diálogos, 17(1), 155-184.

Romano, A. (2009). Transformaciones del discurso pedagógico en el Uruguay de la segunda mitad del siglo XX. II Jornadas de Investigación en Humanidades, 110.

Romano, A. (2010). De la Reforma al Proceso. Una Historia de la Enseñanza Secundaria (1955-1977). Trilce.

Romano, A. (2013). Reconstrucción del debate en torno a la investigación en educación en la década de los 60 en el Uruguay». Políticas Educativas 2. http://seer.ufrgs.br/index.php/Pole/

Schriewer, J. (2011). Sistema mundial y redes de interrelación: La internacionalización de la educación y el papel de la investigación comparada. En Internacionalización. Políticas educativas y reflexión pedagógica en un medio global (pp. 41-105). Granica.

Secretaría de Planeamiento, Coordinación y Difusión. (1978). Sistema, procesos e instrumentos de la planificación en la República Oriental del Uruguay. CEPAL. Boletín de planificación. http://hdl.handle.net/11362/9807

Suasnábar, C. (2013). Intelectuales exilios y educación. Producción intelectual e innovaciones teóricas en educación durante la última dictadura. ProHistoria Editorial.

UNESCO, CEPAL, OEA. (1979). Conferencia regional de ministros de educación y de ministros encargados de la planificación económica de los estados miembros de América Latina y del Caribe.

UNESCO. Oficina Regional de Educación. Chile. (1974). Boletín de educación, (1516).

\section{Notas}

\footnotetext{
${ }^{1}$ La declaración de la OEA pertenecía al Seminario Interamericano sobre Planeamiento Integral de la Educación organizado por OEA y UNESCO en el año 1958. Para Suasnábar, este encuentro puede ser fechado como el momento fundacional de la propuesta de planeamiento integral de la educación, la cual era una reconfiguración de tendencias ya presentes en los países centrales durante los primeros años de la posguerra. Suasnábar, C. (2013). Intelectuales, exilios y educación. Producción intelectual e innovaciones teóricas en educación durante la última dictadura. Prohistoria, p.106.

${ }^{2}$ Hasta 1973 existían en Uruguay cuatro entes de enseñanza autónomos: Enseñanza Primaria, Enseñanza Secundaria, Educación Técnico-Profesional y Universidad de la República. Secundaria estaba dirigida por un Consejo Nacional compuesto por siete miembros: tres electos directamente por los profesores, tres designados por las otras ramas de la enseñanza y el séptimo era el director general.
} 
Este último era propuesto por el propio Consejo y era la única figura que debía contar con la venia del Senado y el presidente de la República.

3 Respaldan esta interpretación los trabajos de: Traversoni, A. y Piotti, D. (1983). Nuestro sistema educativo hoy. Banda Oriental. Rodríguez de Artucio, E., Rampini, M. L., Tornaría, C. y Mazzei, A. (1985). El proceso educativo uruguayo. Dos enfoques del modelo democrático al intento autoritario. Fondo de Cultura Universitaria. Bottaro, J. (1988). El autoritarismo en la enseñanza. CLIP. Campodónico, S., Massera, E. y Sala, N. (1991). Ideología y educación durante la dictadura. Antecedentes, proyecto, consecuencias. Banda Oriental. Romano, A. (2010). De la Reforma al Proceso. Una Historia de la Enseñanza Secundaria (1955-1977). Trilce. Olano, M. E. (2013). El pensamiento político conservador en Uruguay y su relación con los fundamentos doctrinarios del proyecto educativo de la dictadura durante el período comisarial 1973-1976. [Tesis de maestría, Universidad de la República]. https://hdl.handle.net/20.500.12008/8143

${ }^{4}$ La Comisión de Inversiones y Desarrollo Económico fue un organismo público interministerial que funcionó en Uruguay entre 1960 y 1967. Su objetivo fue el desarrollo económico y social del país, utilizando como herramienta la planificación racional de políticas públicas.

${ }^{5}$ Se denominan "cónclaves gubernamentales" a cinco reuniones desarrolladas durante la dictadura, donde autoridades civiles y militares acordaron líneas estratégicas para promover un Plan Nacional de Desarrollo.

${ }^{6}$ Una versión anterior de este trabajo fue presentada en las II Jornadas Académicas del Instituto de Educación de la Facultad de Humanidades y Ciencias de la Educación, Crisis, resistencias y utopías en la educación, en abril de 2021.

${ }^{7}$ La noción de "producción de recursos humanos" es utilizada por Roberto Andreón en 1974 en la revista Prospectiva del MEC, publicación que se realiza con los auspicios del Programa Regional de Desarrollo Educativo de la OEA. Andreón, R. (1974). Educación y cambio. Prospectiva, p.10.

${ }^{8}$ En el Boletín de Planificación del año 1978 de la CEPAL, se publica un trabajo de la Secretaría de Planeamiento, Coordinación y Difusión (SEPLACODI) de Uruguay. El mismo había sido presentado en la Primera Conferencia de Ministros y Jefes de Planificación de América Latina. Secretaría de Planeamiento, Coordinación y Difusión. (1978). Sistema, procesos e instrumentos de la planificación en la República Oriental del Uruguay. CEPAL Boletín de planificación, 2(4-5), 25-37. http://hdl.handle.net/11362/9807

${ }^{9}$ El vicepresidente de esta Conferencia fue el ministro de Educación y Cultura de Uruguay en ese entonces, Daniel Darracq.

${ }^{10}$ Con el ascenso de la nueva ortodoxia neoliberal adoptada por muchos regímenes militares, según Suasnábar, la CEPAL comenzó un proceso de revisión crítica de sus propias perspectivas teóricas y experiencias políticas. En este marco, se fue abandonando la teoría de la dependencia, por un análisis sociopolítico centrado en la relación de las estructuras de poder societal con el desarrollo de los sistemas educativos nacionales. Suasnábar, C. Op. Cit., pp. 231-232.

${ }^{11} \mathrm{La}$ oficina de Planeamiento Educativo del MEC incluía en su estructura un Departamento de Cooperación Técnica, cuyo objetivo era planificar y coordinar proyectos con organismos internacionales. Para ello tenía una sección para la UNESCO, otra para la OEA y una tercera para los restantes Banco Interamericano de Desarrollo, Organización de Estados Iberoamericanos, entre otros. MEC-OEA (1975). Op. Cit., p. 23.

${ }^{12}$ Se define el rendimiento como "la relación existente entre el trabajo realizado por el maestro y los alumnos, por un lado, y la educación -o sea, la perfección intelectual y moral lograda por éstos- del otro." Entre las variables objetivas y normativas se encuentran el nivel intelectual del alumno, su edad, salud y sexo y la dedicación, y experiencia del maestro, así como las actitudes de los padres. MECOEA (1974). Algunos aspectos del rendimiento escolar. IMCO, pp. 10-11.

${ }^{13}$ El Plan Piloto de 1963, se aplicaba en 36 liceos y había sido elaborado a partir de una importante contribución de las Asambleas de Profesores artículo 40. Este organismo institucional asesoraba al Consejo Nacional de Enseñanza Secundaria en los asuntos técnico-pedagógicos y fue eliminado por la ley 14.101.

${ }^{14}$ Se proponen bachilleratos de: administración, agropecuaria, comercial, sanidad, economía, bancos y finanzas, artístico, y otros. Además de aconsejar la flexibilidad de acceder a cualquier carrera universitaria cursando cualquier orientación.

${ }^{15}$ El proyecto hace una propuesta detallada de planes de estudio para el profesorado de Ciclo Básico en Ciencias Sociales, Idioma Español y Literatura. El primero, por ejemplo, incluye 28 asignaturas organizadas en cuatro áreas de formación: histórica, geográfica, económica y socio-política y, la última, de docencia (contenidos psicopedagógicos relativos al rol docente). MEC-OEA, Op. Cit., pp.41-59.

${ }^{16}$ El plan prometía solucionar el problema de atomización del trabajo docente, con la sustitución del sistema de horas-cátedra por cargas horarias de tiempo completo en un solo liceo. En el marco de la History of Education in Latin America - HistELA, v. 4, e25765, 2021, p. 14 de 15 
dictadura, con cientos de profesores destituidos y con violaciones sistemáticas a los derechos individuales, este criterio, resulta más una búsqueda de cooptación, que una preocupación sincera por las condiciones de trabajo docentes. 